\title{
Hormonal Replacement Therapy and the Risk of Lung Cancer in Women: An Adaptive Meta-analysis of Cohort Studies
}

\author{
Jong-Myon Bae, Eun Hee Kim \\ Department of Preventive Medicine, Jeju National University School of Medicine, Jeju, Korea
}

Objectives: Approximately $10 \%$ to $15 \%$ of lung cancer cases occur in never-smokers. Hormonal factors have been suggested to lead to an elevated risk of lung cancer in women. This systematic review (SR) aimed to investigate the association between hormonal replacement therapy (HRT) and the risk of lung cancer in women using cohort studies.

Methods: We first obtained previous SR articles on this topic. Based on these studies we made a list of refereed, cited, and related articles using the PubMed and Scopus databases. All cohort studies that evaluated the relative risk of HRT exposure on lung cancer occurrence in women were selected. Estimate of summary effect size (sES) with 95\% confidence intervals (Cls) were calculated.

Results: A total of 14 cohort studies were finally selected. A random effect model was applied due to heterogeneity (I-squared, 64.3\%). The sES of the 14 articles evaluating the impact of HRT exposure on lung cancer occurrence in women indicated no statistically significant increase in lung cancer risk (sES, $0.99 ; 95 \% \mathrm{Cl}, 0.90$ to 1.09 ).

Conclusions: These results showed that HRT history had no effect on the risk of lung cancer in women, even though the sES of casecontrol studies described in previous SR articles indicated that HRT had a protective effect against lung cancer. It is necessary to conduct a pooled analysis of cohort studies.

Key words: Lung neoplasms, Risk factor, Hormone replacement therapy, Meta-analysis

\section{INTRODUCTION}

Lung cancer is the largest cause of cancer deaths among Koreans [1], and smoking is known to be the main cause of lung cancer $[2,3]$. However, $10 \%$ to $15 \%$ of total lung cancer

Received: September 18, 2015 Accepted: October 28, 2015

Corresponding author: Jong-Myon Bae, MD, PhD

102 Jejudaehak-ro, Jeju 63243, Korea

Tel: +82-64-755-5567, Fax: +82-64-725-2593

E-mail: jmbae@jejunu.ac.kr

This is an Open Access article distributed under the terms of the Creative Commons Attribution Non-Commercial License (http://creativecommons.org/licenses/by$\mathrm{nc} / 3.0 /$ ) which permits unrestricted non-commercial use, distribution, and reproduction in any medium, provided the original work is properly cited. patients have never smoked [4]. It has been argued that neversmokers' lung cancer (NSLCa) should be recognized as a new disease [5] due to its unique epidemiological characteristics, including a high incidence in women and Asian individuals, as well as a higher frequency of adenocarcinomas $[6,7]$.

Factors associated with NSLCa include passive smoking, occupational exposure, atmospheric pollution, past disease history, and genetic sensitivity $[5,6]$. However, the majority of these factors do not explain the epidemiological fact that NSLCa is more common in women. In particular, it has even been reported that passive smoking is unlikely to contribute to the incidence of NSLCa in Asian individuals [8]. As a result, the possibility of a relationship between lung cancer in women and estrogen has been debated, and more specifically, it has been 
proposed that oral contraception and hormone replacement therapy (HRT) may be associated with lung cancer [7,9-13].

With the aim of investigating the association between the HRT history and the occurrence of lung cancer in women, we searched for systematic reviews (SRs) published up to September 2015, and found a total of four such studies (Table 1) [14-17]. The summary effect sizes ( $\mathrm{SES}$ ) with $95 \%$ confidence intervals (Cls) in case-control studies consistently reported a protective effect. In addition, Pesatori et al. [18] performed a pooled analysis of raw data from six case-control studies, and also reported a protective effect (sES, $0.77 ; 95 \% \mathrm{Cl}, 0.66$ to 0.90 ), while consistent results were also confirmed in the case-control studies.

Conversely, the sES of cohort studies presented in Table 1 not only failed to show a consistent findings, but their findings were not statistically significant. Even considering the different endpoints of the literature searches, the four SRs show large differences in the number of cohort studies selected for each meta-analysis, and even show different relative risk (RR) and 95\% Cl values for the same studies in some instances (Table 2). Moreover, of the eleven cohort studies selected by Yao et al. [17], the papers by Adami et al. [19] and Persson et al. [20] were different follow-ups studies of the same cohort participants, and so one of these papers should have been excluded from the meta-analysis. Hence, the aim of the present study was to investigate whether HRT is a risk factor for lung cancer in women using an adaptive meta-analysis of cohort studies.

Table 1. Summary of previous systematic review articles

\begin{tabular}{|c|c|c|c|c|}
\hline \multirow{2}{*}{ Publication cutoff } & Oh (2010) [14] & Greiser (2010) [15] & Chen (2009) [16] & Yao (2013) [17] \\
\hline & Apr 2008 & Jul 2008 & Dec 2008 & May 2012 \\
\hline \multicolumn{5}{|l|}{ Total studies included } \\
\hline $\mathrm{n}$ & 11 & 18 & 12 & 25 \\
\hline sES (95\% Cl) & $0.87(0.74,1.02)$ & & $0.88(0.77,1.01)$ & $0.91(0.83,0.99)$ \\
\hline \multicolumn{5}{|l|}{ Case-control studies } \\
\hline $\mathrm{n}$ & 8 & 9 & 9 & 10 \\
\hline sES $(95 \% \mathrm{CI})$ & $0.81(0.68,0.97)$ & & $0.80(0.73,0.86)$ & $0.81(0.70,0.93)$ \\
\hline \multicolumn{5}{|l|}{ Cohort studies } \\
\hline $\mathrm{n}$ & 3 & 6 & 3 & 11 \\
\hline sES (95\% CI) & $1.01(0.74,1.38)$ & & $1.09(0.99,1.21)$ & $0.94(0.83,1.06)$ \\
\hline \multicolumn{5}{|l|}{ Intervention trials } \\
\hline $\mathrm{n}$ & 0 & 2 & 0 & 4 \\
\hline sES (95\% CI) & & $1.36(1.03,1.79)$ & & $1.18(0.99,1.42)$ \\
\hline
\end{tabular}

sES, summary effect size; $\mathrm{Cl}$, confidence interval.

${ }^{1}$ First author (year of publication) [reference number].

Table 2. Cohort papers included in this study and in the previous four systematic reviews

\begin{tabular}{lcccc}
\hline No. of cohort studies & Oh (2010) [14] & Greiser (2010) [15] & Chen (2009) [16] & Yao (2013) [17] \\
\cline { 2 - 4 } & $\mathbf{3}$ & $\mathbf{6}$ & $\mathbf{3}$ & $\mathbf{1 1}$ \\
\hline Adami (1989) [19] & & $Y$ & $Y$ \\
Persson (1996) [20] & & $Y$ & $Y$ \\
Pukkala (2001) [24] & $Y$ & $Y$ & $Y$ \\
Olsson (2003) [25] & $Y$ & $Y$ & $Y$ \\
Liu (2005) [26] & & & $Y$ \\
Kabat (2007) [27] & $Y$ & $Y$ & $Y$ \\
Corrao (2008) [28] & $Y$ & $Y$ & $Y$ \\
Rodriguez (2008) [29] & & $Y$ \\
Smith (2009) [30] & & $Y$ \\
Slatore (2010) [31] & & $Y$ \\
Clague (2011) [32] & & $Y$ \\
Brinton (2012) [33] & & $Y$ \\
\hline
\end{tabular}

${ }^{1}$ First author (year of publication) [reference number]. 


\section{METHODS}

\section{Search and Selection of Relevant Literature}

Since this study made use of four existing SR papers [14-17], a manually snowballing strategy was used to optimize the efficiency of the literature search [21-23]. Specifically, the literature search was based on the 12 cohort studies [19,20,24-33] used in the four SRs (Table 2), and for each of these studies, a list of the refereed articles as well as "Cited articles", and "Similar (Related) articles", as provided by PubMed (www.ncbi.nlm. nih.gov/pubmed) and Scopus (www.elsevier.com/Scpous), was acquired. September 2015 was the cutoff for publication. In order todetermine the final papers to include in the analysis, the following six exclusion criteria were applied: (1) laboratory studies (2) expert reviews (3) case-control studies (4) intervention trials (5) cohort studies containing no data about HRT and (6) cohort studies analyzing the same participants as another study included in the analysis.

\section{Statistical Analysis}

Two researchers confirmed the study hypothesis of each study and the presence of HRT data for each study, and also extracted the data regarding the risk of lung cancer associated with HRT in each study meeting the selection criteria. Relevant data were identified according to the following priorities: (1) adjusted RR (aRR), controlling for potential confounders, and its $95 \% \mathrm{Cl}$ were the first priority (2) in studies that did not provide an aRR, the crude RR (CRR) and its $95 \% \mathrm{Cl}$ were calculated based on the size of the exposure group and the non-exposure group at the beginning of follow-up and the number of lung cancer patients occurring in each group during follow-up (3) when the RR was still not clear, data presented in an SR were used. In such cases, after assessing heterogeneity using the I-squared value (\%), a meta-analysis using a random effect model was performed on studies with I-squared $\geq 50 \%$, obtaining sES and its $95 \% \mathrm{Cl}$. Additionally, publication bias was assessed using symmetry of the funnel plot and Egger's regression. A subgroup analysis was performed based on the risk data by dividing studies into those where aRR was available and those where it was not. A $p$-value $<0.05$ was considered to indicate statistical significance, and the StataSE version 14.0 (Stata Corp., College Station, TX, USA) were used to perform the statistical analysis.

\section{RESULTS}

Figure 1 displays the selection process of the studies that were ultimately included in this review. A total of 126 potential papers were identified through hand searching, from which 112 papers were excluded, resulting in a final selection of 14 cohort studies. Two papers were excluded because they derived their data from the same cohort as another study. The study by Adami et al. [19] used the same participants as Persson et al. [20], and Adami et al. [19] was excluded due to its shorter follow-up period. Brinton et al. [33] used the same cohort as Brinton et al. [34], and the most recently published of these two papers was included.

Table 3 displays the data source, nation, follow-up period, aRR/cRR, and $95 \% \mathrm{Cl}$ for the 14 cohort studies that were ultimately included. Tem of these studies [20,24-32] were included in the four SRs presented in Table 1, while the other four [3437] were newly selected using the snowballing search method.

Figures 2 and 3 are the forest plot and funnel plot obtained from our meta-analysis of the 14 studies. Since the I-squared value was $64.3 \%$, a random effect model was used, and the results showed that the association between HRT and lung cancer was not statistically significant (sES, $0.99 ; 95 \% \mathrm{Cl}, 0.90$ to 1.09). The funnel plot was not symmetrical, and the Egger regression analysis showed an effect in the small-scale studies (beta $=1.7, p=0.016$ ). Meta-analysis of the six studies providing information about aRR $[26,27,30,32,35,36]$ showed an sES

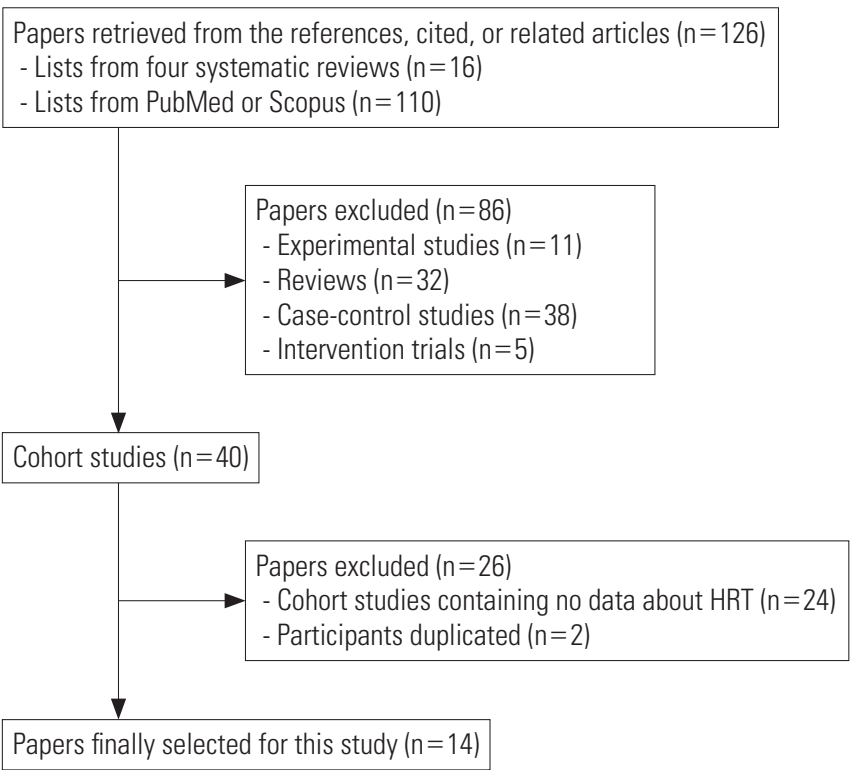

Figure 1. Flow chart of the selection of articles for inclusion in this study. 


\section{Journal of}

Table 3. Summary of selected cohort articles?

\begin{tabular}{|c|c|c|c|c|c|c|}
\hline & Nation & Source & Years of follow-up & Type $^{2}$ & $\mathbf{R R}$ & $95 \% \mathrm{Cl}$ \\
\hline Persson (1996) [20] & Sweden & Uppsala Health Care Region & 1981-1991 & 2 & 1.00 & $0.82,1.22$ \\
\hline Pukkala (2001) [24] & Finland & National Social Insurance Institution & 1994-1997 & 2 & 0.85 & $0.59,1.21$ \\
\hline Olsson (2003) [25] & Sweden & South Swedish Health Care Region & 1993-1999 & 2 & 1.43 & $0.68,3.02$ \\
\hline Liu (2005) [26] & Japan & Japan Public Health Center-based prospective study & 1990-2002 & 1 & 1.46 & $0.92,2.32$ \\
\hline Kabat (2007) [27] & Canada & Canadian National Breast Screening Study & $1986-2000$ & 1 & 1.07 & $0.90,1.27$ \\
\hline Corrao (2008) [28] & Italy & National Health Service & $2001-2005$ & 3 & 0.99 & $0.82,1.19$ \\
\hline Rodriguez (2008) [29] & USA & Cancer Prevention Study II Nutrition Cohort & $1992-2003$ & 2 & 0.96 & $0.82,1.11$ \\
\hline Weiss (2008) [35] & China & Shanghai Womens' Health Study & $2001-2004$ & 1 & 0.50 & $0.16,1.56$ \\
\hline Seow (2009) [36] & Singapore & Singapore Chinese Health Study & 1999-2005 & 1 & 1.38 & $0.76,2.50$ \\
\hline Smith (2009) [30] & USA & Rancho Bernardo cohort study & $1975-2005$ & 1 & 1.13 & $0.73,1.74$ \\
\hline Baik (2010) [37] & USA & Nurses' Health Study & $1984-2006$ & 2 & 1.01 & $0.90,1.13$ \\
\hline Slatore (2010) [31] & USA & Vitamins \& lifestyle study & $2003-2007$ & 2 & 1.11 & $0.88,1.40$ \\
\hline Brinton (2011) [34] & USA & NIH-AARP Diet and Health Study Cohort & 1997-2006 & 2 & 0.80 & $0.75,0.85$ \\
\hline Clague (2011) [32] & USA & California Teachers Study & 1995-2007 & 1 & 0.95 & $0.80,1.13$ \\
\hline
\end{tabular}

$\mathrm{RR}$, relative risk; $\mathrm{Cl}$, confidence interval.

${ }^{1}$ First author (year of publication) [reference number].

${ }^{2}$ Type of information (1, adjusted relative risk; 2 , crude relative risk; 3 , copied from the systematic review).

Study

ID

ES $(95 \%$ CI)

Weight

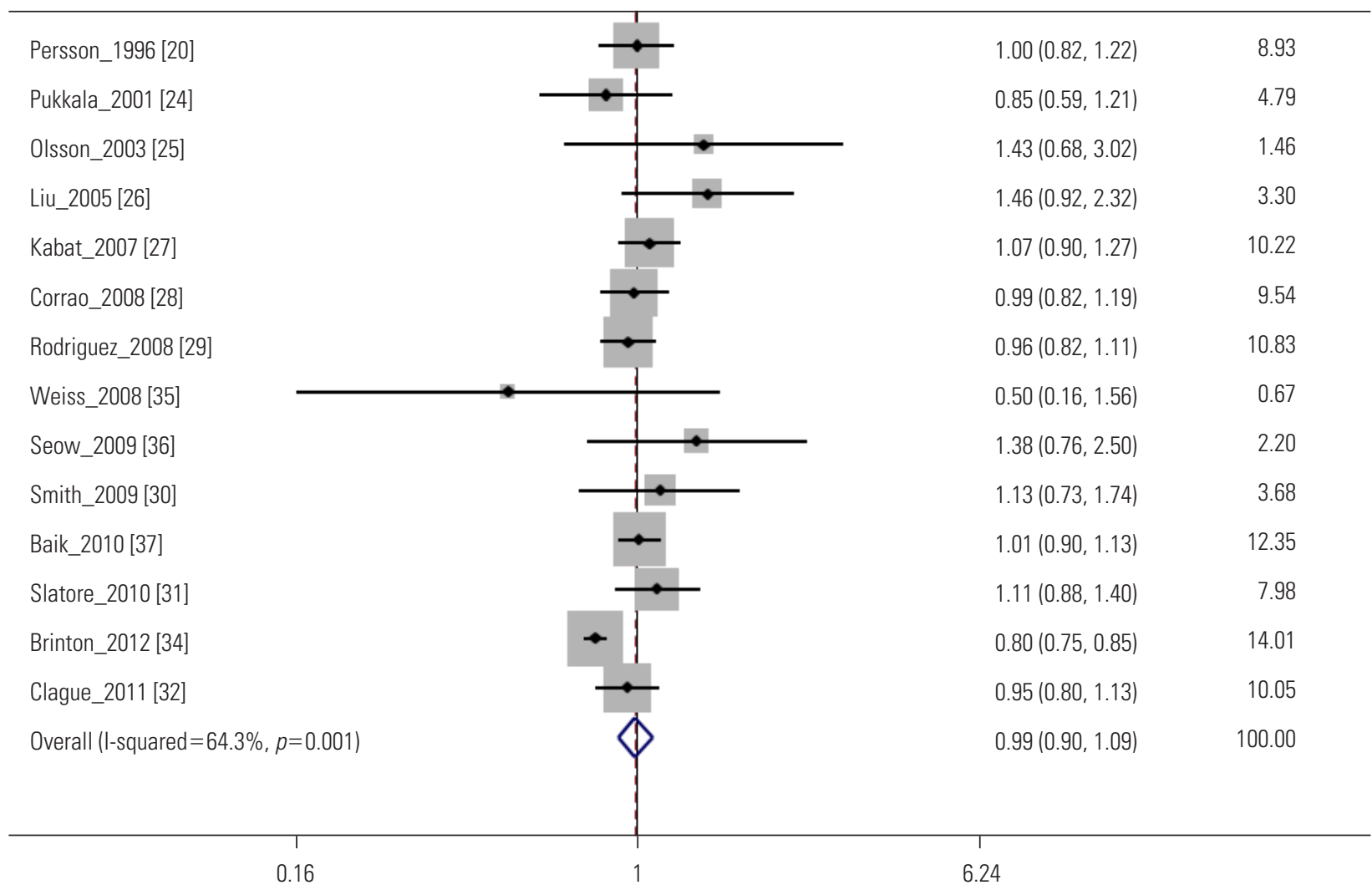

Figure 2. Forest plot made using random-effects summary estimates for 14 cohort articles. ID, name of first author_year of publication [reference number]; ES, effect size; $\mathrm{Cl}$, confidence interval. 
Funnel plot with pseudo 95\% confidence limits

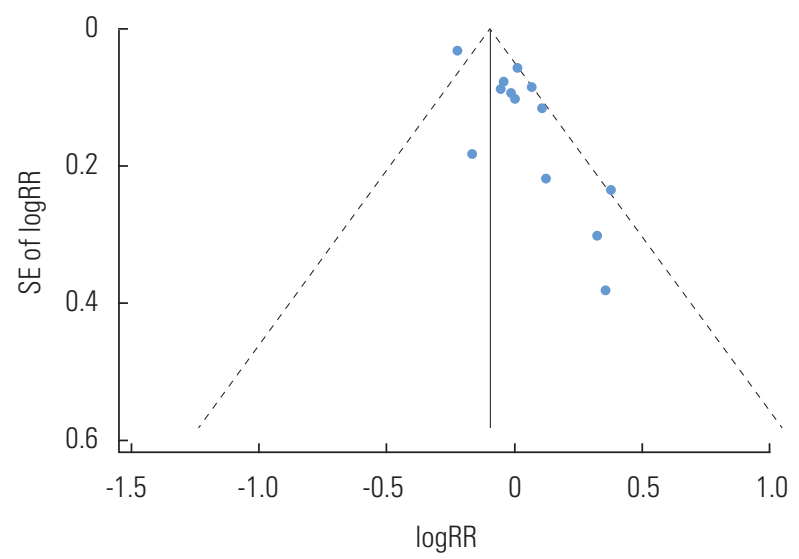

Figure 3. Funnel plot (Egger regression; beta $=1.7, p=0.016$ ). $\log R R$, log relative risk; SE of logRR, standard error of log relative risk.

of $1.05(95 \% \mathrm{Cl}, 0.92$ to 1.20 ; I-squared, $14.3 \%)$, and the remaining eight studies $[20,24,25,28,29,31,34,37]$ showed an $\mathrm{SES}$ of 0.99 ( $95 \% \mathrm{Cl}, 0.90$ to 1.09 ; I-squared, $70.4 \%$ ) (data not shown).

\section{DISCUSSION}

The limitations of the existing 4 SRs included non-replication of the selected studies, different RR values reported for the same studies, lack of statistical significance in cohort studies, and the need to update the results due to the May 2012 end date of the literature search. Therefore, in order to overcome these limitations, we performed a hand search ending in September 2015. Nevertheless, the results were still not statistically significant. To summarize, in SR research using observational studies, the case-control studies showed a significance protective association between HRT and lung cancer in women, but the cohort studies showed no association whatsoever $[24,38,39]$.

The present study used the previous SRs rather than a search of electronic databases, and applied a snowballing search method using referred, cited and related papers. These methods led to the inclusion of an additional four studies [34-37]. However, since the publication dates of those studies were between 2008 and 2010, in theory they should have been selected in the SR by Yao et al. [17], which incorporated studies published by May 2012. This finding demonstrates the utility of a snowballing search strategy based on previous SRS, using lists of referred, cited, and related articles.

Siegrfied [40] summarized the pre-clinical and post-treat- ment evidences suggesting estrogen to be a risk factor and a prognostic factor for lung cancer. A recent pooled analysis of six case-control studies reported that HRT reduced lung cancer risk [18], but the present SR of 14 cohort studies found no statistically significant association. This discrepancy could be explained by the different of HRT duration reflected in casecontrol studies and cohort studies [40]. Thus, further epidemiological analysis incorporating HRT duration instead of a binary classification of each subject's HRT history is necessary.

In conclusion, this adaptive meta-analysis of cohort studies did not showed a statistically significant association between HRT and lung cancer risk in women. In spite of the broader search strategy, if the appropriate information cannot be obtained from the selected papers, the validity of the meta-analysis will inevitably be compromised. In the present study, since aRR was available in only six studies (43\%), a subgroup analysis was performed, and no significantly different findings were observed. Ultimately, a pooled analysis of cohort databases will be required to overcome this limitation $[23,41]$.

\section{CONFLICT OF INTEREST}

The authors have no conflicts of interest associated with the material presented in this paper.

\section{REFERENCES}

1. Jung KW, Won YJ, Kong HJ, Oh CM, Cho H, Lee DH, et al. Cancer statistics in Korea: incidence, mortality, survival, and prevalence in 2012. Cancer Res Treat 2015;47(2):127-141.

2. Bae JM, Li ZM, Shin MH, Kim DH, Lee MS, Ahn YO. Lung cancer incidence by smoking status in Korean men: 16-years of observations in the Seoul Male Cancer Cohort study. J Korean Med Sci 2013;28(4):636-637.

3. Dela Cruz CS, Tanoue LT, Matthay RA. Lung cancer: epidemiology, etiology, and prevention. Clin Chest Med 2011;32(4):605644.

4. Thun MJ, Henley SJ, Burns D, Jemal A, Shanks TG, Calle EE. Lung cancer death rates in lifelong nonsmokers. J Natl Cancer Inst 2006;98(10):691-699.

5. Planchard D, Besse B. Lung cancer in never-smokers. Eur Respir J 2015;45(5):1214-1217.

6. Alberg AJ, Wallace K, Silvestri GA, Brock MV. Invited commentary: the etiology of lung cancer in men compared with women. Am J Epidemiol 2013;177(7):613-616. 
7. Subramanian J, Govindan R. Lung cancer in 'Never-smokers': a unique entity. Oncology (Williston Park) 2010;24(1):29-35.

8. Krishnan VG, Ebert PJ, Ting JC, Lim E, Wong SS, Teo AS, et al. Whole-genome sequencing of asian lung cancers: secondhand smoke unlikely to be responsible for higher incidence of lung cancer among Asian never-smokers. Cancer Res 2014; 74(21):6071-6081.

9. Chakraborty S, Ganti AK, Marr A, Batra SK. Lung cancer in women: role of estrogens. Expert Rev Respir Med 2010;4(4):509-518.

10. Subramanian J, Govindan R. Lung cancer in never smokers: a review. J Clin Oncol 2007;25(5):561-570.

11. Sun S, Schiller JH, Gazdar AF. Lung cancer in never smokers--a different disease. Nat Rev Cancer 2007;7(10):778-790.

12. Siegfried JM. Women and lung cancer: does oestrogen play a role? Lancet Oncol 2001;2(8):506-513.

13. Meireles SI, Esteves GH, Hirata R Jr, Peri S, Devarajan K, Slifker $M$, et al. Early changes in gene expression induced by tobacco smoke: evidence for the importance of estrogen within lung tissue. Cancer Prev Res (Phila) 2010;3(6):707-717.

14. Oh SW, Myung SK, Park JY, Lym YL, Ju W. Hormone therapy and risk of lung cancer: a meta-analysis. J Womens Health (Larchmt) 2010;19(2):279-288.

15. Greiser CM, Greiser EM, Dören M. Menopausal hormone therapy and risk of lung cancer-Systematic review and meta-analysis. Maturitas 2010;65(3):198-204.

16. Chen X, Cai L. Meta-analysis of the effects on hormone replacement therapy and oral contraceptives associated with female lung cancer risk. Wei Sheng Yan Jiu 2009;38(6):672-676 (Chinese).

17. Yao Y, Gu X, Zhu J, Yuan D, Song Y. Hormone replacement therapy in females can decrease the risk of lung cancer: a metaanalysis. PLoS One 2013;8(8):e71236.

18. Pesatori AC, Carugno M, Consonni D, Hung RJ, Papadoupolos A, Landi MT, et al. Hormone use and risk for lung cancer: a pooled analysis from the International Lung Cancer Consortium (ILCCO). Br J Cancer 2013;109(7):1954-1964.

19. Adami HO, Persson I, Hoover R, Schairer C, Bergkvist L. Risk of cancer in women receiving hormone replacement therapy. Int J Cancer 1989;44(5):833-839.

20. Persson I, Yuen J, Bergkvist L, Schairer C. Cancer incidence and mortality in women receiving estrogen and estrogen-progestin replacement therapy--long-term follow-up of a Swedish cohort. Int J Cancer 1996;67(3):327-332.

21. Bae JM. Narrative reviews. Epidemiol Health 2014;36:e2014018.

22. Bae JM. Human papillomavirus 16 infection as a potential risk factor for prostate cancer: an adaptive meta-analysis. Epide- miol Health 2015;37:e2015005.

23. Bae JM. The necessity of an observational study on the interactions between allergic history and citrus fruit intake for the prevention of pancreatic cancer. Epidemiol Health 2015;37: e2015028.

24. Pukkala E, Tulenheimo-Silfvast A, Leminen A. Incidence of cancer among women using long versus monthly cycle hormonal replacement therapy, Finland 1994-1997. Cancer Causes Control 2001;12(2):111-115.

25. Olsson H, Bladström A, Ingvar C. Are smoking-associated cancers prevented or postponed in women using hormone replacement therapy? Obstet Gynecol 2003;102(3):565-570.

26. Liu Y, Inoue M, Sobue T, Tsugane S. Reproductive factors, hormone use and the risk of lung cancer among middle-aged never-smoking Japanese women: a large-scale populationbased cohort study. Int J Cancer 2005;117(4):662-666.

27. Kabat GC, Miller AB, Rohan TE. Reproductive and hormonal factors and risk of lung cancer in women: a prospective cohort study. Int J Cancer 2007;120(10):2214-2220.

28. Corrao G, Zambon A, Conti V, Nicotra F, La Vecchia C, Fornari C, et al. Menopause hormone replacement therapy and cancer risk: an Italian record linkage investigation. Ann Oncol 2008; 19(1):150-155.

29. Rodriguez C, Spencer Feigelson H, Deka A, Patel AV, Jacobs EJ, Thun MJ, et al. Postmenopausal hormone therapy and lung cancer risk in the cancer prevention study II nutrition cohort. Cancer Epidemiol Biomarkers Prev 2008;17(3):655-660.

30. Smith JR, Barrett-Connor E, Kritz-Silverstein D, Wingard DL, AlDelaimy WK. Hormone use and lung cancer incidence: the Rancho Bernardo cohort study. Menopause 2009;16(5):10441048.

31. Slatore CG, Chien JW, Au DH, Satia JA, White E. Lung cancer and hormone replacement therapy: association in the vitamins and lifestyle study. J Clin Oncol 2010;28(9):1540-1546.

32. Clague J, Reynolds P, Sullivan-Halley J, Ma H, Lacey JV Jr, Henderson KD, et al. Menopausal hormone therapy does not influence lung cancer risk: results from the California Teachers Study. Cancer Epidemiol Biomarkers Prev 2011;20(3):560-564.

33. Brinton LA, Schwartz L, Spitz MR, Park Y, Hollenbeck AR, Gierach GL. Unopposed estrogen and estrogen plus progestin menopausal hormone therapy and lung cancer risk in the $\mathrm{NIH}$ AARP Diet and Health Study Cohort. Cancer Causes Control 2012;23(3):487-496.

34. Brinton LA, Gierach GL, Andaya A, Park Y, Schatzkin A, Hollenbeck $A R$, et al. Reproductive and hormonal factors and lung 
cancer risk in the NIH-AARP Diet and Health Study cohort. Cancer Epidemiol Biomarkers Prev 2011;20(5):900-911.

35. Weiss JM, Lacey JV Jr, Shu XO, Ji BT, Hou L, Yang G, et al. Menstrual and reproductive factors in association with lung cancer in female lifetime nonsmokers. Am J Epidemiol 2008; 168(11):1319-1325.

36. Seow A, Koh WP, Wang R, Lee HP, Yu MC. Reproductive variables, soy intake, and lung cancer risk among nonsmoking women in the Singapore Chinese Health Study. Cancer Epidemiol Biomarkers Prev 2009;18(3):821-827.

37. Baik CS, Strauss GM, Speizer FE, Feskanich D. Reproductive factors, hormone use, and risk for lung cancer in postmenopausal women, the Nurses' Health Study. Cancer Epidemiol Biomark- ers Prev 2010;19(10):2525-2533.

38. Bae JM, Lee EJ, Guyatt G. Citrus fruit intake and stomach cancer risk: a quantitative systematic review. Gastric Cancer 2008; 11(1):23-32.

39. Bae JM, Lee EJ, Guyatt G. Citrus fruit intake and pancreatic cancer risk: a quantitative systematic review. Pancreas 2009;38(2): 168-174.

40. Siegfried JM. Smoking out reproductive hormone actions in lung cancer. Mol Cancer Res 2014;12(1):24-31.

41. Koushik A, Spiegelman D, Albanes D, Anderson KE, Bernstein L, van den Brandt PA, et al. Intake of fruits and vegetables and risk of pancreatic cancer in a pooled analysis of 14 cohort studies. Am J Epidemiol 2012;176(5):373-386. 